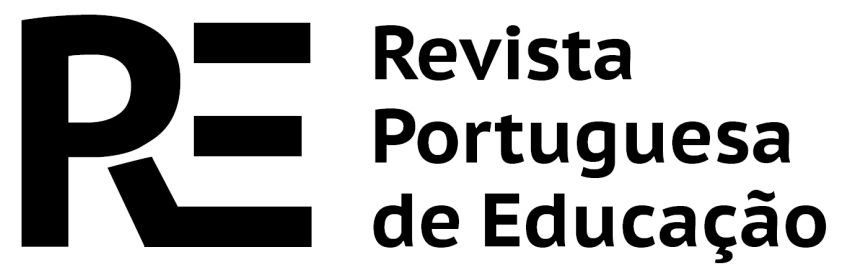

\title{
Educação Inclusiva: Proposta de quadro analítico e aplicação ao caso português
}

\begin{abstract}
RESUMO
O conceito de educação inclusiva tem vindo a ganhar inegável centralidade no plano das políticas educativas. A partir da identificação de um conjunto de linhas teóricas e de investigação sobre o tema, o presente artigo propõe um quadro de análise para discutir os progressos, fragilidades e desafios de sistemas e programas educativos comprometidos com o desígnio da educação inclusiva, aplicando esse quadro para discutir a evolução do sistema educativo português nas duas primeiras décadas do século XXI. Desta forma, observamse alguns avanços importantes, mas também hiatos persistentes, incluindo ao nível da produção sistemática de informação e conhecimento.
\end{abstract}

Palavras-chave: Inclusão; Políticas; Aprendizagem; Indicadores

\section{INTRODUÇÂO}

De referências residuais até aos anos 1980, o conceito de "educação inclusiva" tem vindo a afirmar-se e ocupa hoje um lugar central nas políticas educativas, a nível internacional. Nas Nações Unidas, por exemplo, o conceito surge em declarações específicas relativas à deficiência e às necessidades educativas especiais, nos anos 1990, sendo adotado em 2015 na designação do objetivo 4 da agenda global para o desenvolvimento sustentável: "assegurar uma educação inclusiva, equitativa e de qualidade e proporcionar oportunidades de aprendizagem ao longo da vida para todos". O mesmo movimento é visível em Portugal, estando ausente da Lei de Bases do Sistema Educativo e tendo sido recentemente adotado enquanto princípio basilar da organização do sistema, através do Decreto-Lei n.o $54 / 2018$.

Neste contexto, o presente artigo parte de um enquadramento teórico, no qual se discutem várias perspetivas que a investigação educacional tem vindo a produzir, a nível nacional e internacional, sobre este conceito. Em seguida, propõe-se um modelo de análise que permita observar a situação de um país, região ou município ao nível da educação inclusiva. Finalmente, discute-se a evolução recente do sistema educativo português à luz deste modelo, 
mobilizando-se indicadores existentes, destacando outros que seriam relevantes e refletindo-se sobre desafios que se colocam à plena concretização deste conceito.

Procura-se contribuir desta forma para a definição de uma baseline para o modelo estabelecido pelo novo enquadramento normativo, ou seja, em que ponto nos encontramos na garantia de uma educação inclusiva a todos os cidadãos. Reflete-se igualmente sobre quais os indicadores mais adequados para aferir o carácter inclusivo do sistema educativo, das suas organizações e políticas. Tal como nota um relatório recente (AENEEI, 2018), existe ainda uma escassez de dados que permitam analisar as políticas de educação inclusiva e os seus impactos, o que limita a capacidade de alargar, consolidar e melhorar essas políticas.

\section{PERSPETIVAS TEÓRICAS SOBRE A EDUCAÇÃO INCLUSIVA}

A crescente importância do conceito de educação inclusiva nas políticas públicas foi concomitante com um avolumar da reflexão e da investigação, no seio das ciências da educação, dando origem a diferentes conceptualizações. Sem pretensões de exaustividade, destacamos aqui cinco linhas de argumentação e de pesquisa relevantes para compreender esta mudança conceptual. De referir que as perspetivas seguintes não são necessariamente concorrentes e combinam-se, em intensidades e variantes diversas, no trabalho de vários autores. Desta forma, a tipologia serve, sobretudo, propósitos heurísticos e expositivos.

Uma primeira perspetiva é aquela que traça uma sequência de etapas históricas que modelaram a instituição escolar, em articulação com a transformação dos quadros sociais e políticos, partindo da exclusão da diferença, passando pela segregação em instituições "especiais", posteriormente, pela integração em escolas "regulares" com o apoio de professores especializados (capazes de adequar o ensino a "necessidades educativas especiais"), até à adoção recente de um princípio de educação inclusiva que assume que todos os alunos são diferentes e essa diversidade é, ela própria, um valor fundamental que as escolas devem respeitar, mobilizar e potenciar (Casanova, 2018; Porter, 2014; Silva, 2009). Estes autores tendem a enfatizar que esta mudança implica um conjunto de reajustes organizacionais, assim como programas alargados de formação dos professores para se adequarem ao novo paradigma.

Numa segunda perspetiva, o conceito de educação inclusiva pressupõe uma desconstrução crítica do (ou rutura com o) modelo de escola e de ensino-aprendizagem que dominou os séculos anteriores e que incluiu a formação de profissionais e o desenvolvimento de programas específicos para aqueles que revelavam "necessidades especiais" (Barton, 1997; Freire, 2008; Rodrigues, 2006; Sanches \& Teodoro, 2006; Strieder \& Nogaro, 2016; Thomas, 2013; Vlachou, 2004). Segundo estes autores, a educação inclusiva - diferente de inclusão educativa - está necessariamente vinculada a princípios de justiça e transformação social, assim como a uma visão da escola enquanto comunidade de aprendizagem, na qual todos os profissionais e alunos participam, são reconhecidos e aprendem uns com os outros, o que acarreta mudanças institucionais profundas. Tal rutura ou desconstrução afiguram-se tanto mais difíceis num tempo em que se têm afirmado igualmente modelos educativos que, ao promoverem a estandardização dos currículos e da avaliação, bem como a competição entre alunos e entre escolas, contribuem para práticas que são contrárias aos princípios da educação inclusiva. 
Uma terceira linha de investigação tem vindo a questionar o desenvolvimento deste conceito, no âmbito de políticas educativas de ascendente neoliberal (Hardy \& Woodcock, 2015; Waitoller \& Kozleski, 2015). Nesta perspetiva, o conceito de educação inclusiva constitui uma retórica atrativa e que pode legitimar uma redução da despesa pública com instituições e profissionais especializados, sobrecarregando os professores generalistas, com a ilusão de que estes teriam capacidade de ensinar todos os alunos, em turmas heterogéneas e independentemente das suas dificuldades e condições específicas. As famílias com meios económicos privilegiados podem sempre recorrer a instituições privadas mais capazes de ter uma oferta qualificada para as singularidades dos seus filhos, deixando uma escola pública low cost e indiferenciada para os filhos das classes trabalhadoras. Ao aglomerar indistintamente as dificuldades de integração e sucesso escolar resultantes de uma vasta gama de fatores - incluindo também a exclusão social, as desigualdades de classe, as pertenças étnicas, etc. - o conceito de educação inclusiva permitiria, aliás, dissimular, despolitizar e psicologizar os conflitos sociais e as desigualdades de poder que estão na sua base, substituindo o princípio incómodo de igualdade de oportunidades pelo princípio mais flexível de inclusão e criando a ideia de que são os professores e os alunos, em cada sala de aula, que podem e devem resolver tais desigualdades, brechas e tensões. Nesta perspetiva, a educação inclusiva tenderia a impor-se como inquestionável, sendo raras as políticas nesta área assentes em evidências sobre os contextos e as condições em que os alunos aprendem efetivamente mais e melhor.

Um quarto filão de estudos é centrado na relação entre políticas curriculares e educação inclusiva (Pacheco, 2016; Seabra, 2017). Se o movimento internacional de estandardização dos currículos e da avaliação e consequente competição-hierarquização dos alunos, dos professores, das escolas e dos sistemas educativos dificilmente é compaginável com um princípio de educação inclusiva, pela sua vocação para segregar e excluir, em oposição, a diversificação curricular, presente em múltiplas formas de conceção, desenvolvimento e avaliação dos percursos de aprendizagem, sem os traduzir em desigualdades, pode ser a via mais efetiva para um compromisso da educação com a inclusão. Isto pressupõe pensar o currículo (e a avaliação) de forma diferente, não como um sistema uniforme e definido centralmente, mas como uma (re)construção em contexto. E, tal como notam Rajput et al. (2018), implica analisar que autonomia, formação e recursos têm os docentes para efetivamente realizar esse trabalho em sala de aula.

Por fim, assumindo que o próprio conceito de educação inclusiva e, sobretudo, a sua concretização são muito variáveis consoante os contextos, uma quinta linha de estudos, mais pragmática, tem procurado desenvolver indicadores que permitam analisar e comparar as mudanças produzidas no terreno, ao abrigo deste conceito (Ainscow \& César, 2006). Esse desígnio tem passado por examinar as evoluções, em determinados territórios e períodos temporais, focando aspetos tais como as alterações legislativas (Pereira et al., 2018; Rodrigues \& Nogueira, 2010), o financiamento dos sistemas (Johnstone et al., 2018), as lideranças (Neiva et al., 2017), as práticas e representações dos profissionais educativos (Alonso et al., 2015; Borges et al., 2017; Rodrigues \& Ferreira, 2017; Sampaio \& Morgado, 2015), as aprendizagens, atitudes e interações entre alunos (Dias et al., 2016; Haug, 2017). Nesta perspetiva, a questão central é compreender de que forma o conceito tem vindo a ser interpretado no quadro das políticas educativas e em que medida tem contribuído para reduzir as desigualdades e a exclusão. 


\section{EM BUSCA DE UM MODELO DE ANÁLISE SISTÉMICA}

O modelo que aqui se propõe tem por base as várias perspetivas referidas no ponto anterior: (1) assume que a transformação socio-histórica dos sistemas educativos é progressiva, mas com pontos de inflexão e resulta de distintos movimentos em tensão; (2) procura entender se efetivamente este conceito tem dado origem a transformações profundas e integrais na instituição escolar; (3) pondera a apropriação deste conceito no quadro de políticas mais amplas e globais, discutindo criticamente os indicadores que o sistema atualmente disponibiliza; (4) coloca uma atenção específica no acesso de todos ao currículo, em condições de igualdade; e (5) procura examinar efeitos concretos das políticas, neste caso, explorando o caso português.

Assim sendo, o modelo proposto baseia-se em cinco condições centrais, enumeradas de (a) a (e) no tópico seguinte. De referir que não subentendemos qualquer hierarquia ou procedência entre elas. Em certas circunstâncias, podem existir aprendizagens dos alunos sem integração em escolas "regulares" e vice-versa. Pode existir reconhecimento de diferentes culturas sem sucesso escolar ou, até, sem frequência escolar e vice-versa. Contudo, consideramos essas sempre soluções incompletas, dentro de um modelo efetivo de educação inclusiva, ou seja, apenas o cumprimento integrado das cinco condições permitirá designar um sistema (ou programa) enquanto inclusivo. 0 que aqui pretendemos focar é, portanto, o que deve garantir um sistema de educação inclusiva e, em que medida, podemos aferir se nos estamos a aproximar ou não desse desígnio, tendo em conta que as políticas e práticas educativas se encontram sujeitas a múltiplas pressões, retóricas e movimentos, em sentidos quantas vezes divergentes.

Em concordância com as perspetivas teóricas apresentadas, procura-se reconstituir uma visão do sistema como um todo, evitando o enfoque exclusivo em certos grupos de alunos (Messiou, 2017). Aliás, será essa uma das principais diferenças do modelo normativo adotado em 2018, em Portugal, face aos anteriores. Contudo, tanto quanto possível num artigo exploratório, procuramos atender a especificidades dos diferentes perfis de alunos, ponderando em que medida o sistema tem encontrado respostas para garantir a sua inclusão. Por fim, reconhece-se este como um processo socio-histórico complexo e multidimensional, com avanços e recuos. Também por isso é fundamental não perder a capacidade de uma visão integrada e de "séries longas".

\section{UMA ANÁLISE EXPLORATÓRIA DO CARÁCTER INCLUSIVO DO SISTEMA EDUCATIVO PORTUGUÊS}

O modelo proposto organiza-se então nas seguintes cinco dimensões, sendo que a análise de cada uma delas parte de indicadores e estudos existentes, sem deixar de questionar a necessidade de outros indicadores e de sugerir linhas de pesquisa para o futuro.

\section{(a) GARANTIR O ACESSO E A FREQUÊNCIA ESCOLAR EFETIVA}

A educação inclusiva implica que todas as crianças frequentem efetivamente a escola. $\mathrm{O}$ indicador mais robusto e comparável - designado abandono precoce da educação e formação, aferido pelo Instituto Nacional de Estatística de acordo com os critérios definidos pelo Eurostat - tem revelado uma evolução singular do nosso país, ao longo das últimas duas décadas. Em 2002, 45\% dos jovens abandonavam a escola sem completar a escolaridade secundária $\left(12^{\circ}\right.$ 
ano), valor que se reduziu para 8,9\% em 2020, alcançando a média europeia progresso para o qual contribuíram políticas educativas assim como de combate ao trabalho infantil, de reinserção, de segurança e de solidariedade social (Álvares et al., 2017).

Num quadro em que se pretende garantir o acesso universal à educação, um valor próximo aos 10\% é ainda significativo e a metodologia seguida pelo INE/Eurostat coloca limitações a análises mais refinadas que permitam, por exemplo, aferir a sua concentração em territórios, idades, grupos e perfis de jovens, incluindo aqueles que são sinalizados pelas escolas com necessidade de um projeto educativo individualizado. Existem evidências parcelares de níveis elevados de abandono, por exemplo, nas comunidades ciganas (DGEEC, 2018a) ou em certos territórios do país (CNE, 2018).

Importa igualmente ponderar a partir de que ponto a ausência de assiduidade e/ou pontualidade constituem um problema efetivo de acesso à educação. Estudos em contextos vulneráveis têm observado um número considerável de alunos a quem a frequência irregular, desde o 1o ciclo do ensino básico, compromete o percurso e oportunidades de aprendizagem (e.g. Abrantes et al., 2013; Fernandes et al., 2018). Mas não existem dados rigorosos, em termos de escolas, condição socioeconómica, nacionalidade ou sinalização no âmbito da educação inclusiva.

Outra situação, prevista na lei portuguesa e sobre a qual subsiste alguma escassez de dados, é a das crianças inscritas nas modalidades de ensino doméstico e ensino individual. Se a educação inclusiva tem sido associada ao objetivo de garantir o acesso de todas as crianças às escolas "regulares", como se coaduna com o direito das famílias a inscrever os seus filhos em modalidades que os excluem deliberadamente do acesso a qualquer tipo de escola? Será importante saber quantos alunos se encontram nesta situação, qual o perfil destas crianças e famílias, quais os motivos, quais as práticas educativas em que participam, quais as aprendizagens que realizam e quais os seus percursos após a maioridade. A Portaria n. ${ }^{\circ}$ 69/2019 prevê a supervisão da escola aos projetos educativos e aprendizagens dos alunos, sendo importante conhecer os seus resultados.

Por fim, é questionável se o enfoque no grupo etário dos 6 aos 18 é suficiente. Apesar de ser hoje reconhecido que o acesso a instituições educativas em idades mais precoces tem um impacto positivo nas aprendizagens e desenvolvimento, a garantia do acesso à educação dos 3 aos 6 anos confrontase ainda com o carácter não obrigatório e com a escassez de vagas, em alguns territórios, situação mais preocupante se observarmos o segmento dos 0 aos 3 anos (Eurydice, 2019). Por outro lado, subsiste o debate acerca do modo de concretização do direito à aprendizagem ao longo da vida, bem como alguma escassez de dados periódicos acerca da oferta, em todo o território e que permita cobrir as (diferentes) necessidades educativas da população. Em termos quantitativos, após um pico de frequência entre 2008 e 2011, a educação de adultos voltou a ter uma expressão residual, tendo conhecido desde 2016 um novo crescimento, mas que a pandemia parece travado (DGEEC, 2021). Em todo o caso, o número anual de adultos em educação e formação não tem superado os 100.000 , num total de população adulta sem o ensino secundário completo que ronda os 4 milhões.

\section{(b) GARANTIR AS APRENDIZAGENS E AS QUALIFICAÇÕES}

0 acesso generalizado à escolaridade não é suficiente para definir uma educação inclusiva. Outro elemento fundamental é que o sistema educativo permita 
a todos realizar aprendizagens significativas, desenvolver-se enquanto pessoas e cidadãos, inserir-se no tecido social e económico. Na sociedade atual, a aquisição de competências básicas e títulos escolares é fundamental para escapar a processos estruturais de exclusão e desqualificação social (Abrantes, 2013).

Assumindo o $12^{\circ}$ ano como a qualificação mínima prevista hoje para as novas gerações, obtida através de cursos científico-humanísticos ou de cursos de dupla certificação (escolar e profissional), podemos constatar que, em $2017,22,5 \%$ dos jovens entre os 20 e os 24 anos não tinham completado este nível educativo, segundo os dados do Inquérito ao Emprego (INE/Eurostat), o que os deixa numa situação fragilizada. É certo que a evolução foi notável nos últimos anos (apenas em 2007 foi ultrapassada a fasquia dos 50\%). Mas será importante compreender a expressão que esta situação adquire em determinados grupos desfavorecidos, tais como os ciganos e afrodescendentes, aqueles que revelam necessidades educativas especiais, crescem em famílias mais pobres ou em territórios marginalizados.

As taxas de retenção, historicamente massivas em Portugal (CasaNova 2005), conheceram um retrocesso significativo, de $12,7 \%$ no ensino básico e 39,4\% no ensino secundário, em 2001, para 2,2\% e 8,5\%, em 2020 (DGEEC, 2021). Uma evolução que, ainda assim, significa que cerca de 70 mil alunos, em Portugal, não realizaram as aprendizagens esperadas e ficaram retidos. Uma análise mais fina permite constatar que a retenção atinge cerca de 11\% dos alunos ciganos (DGEEC, 2020), logo no 1ำ ciclo do ensino básico, numa etapa inicial em que ronda apenas os $2 \%$ dos alunos no total nacional. E ultrapassa os $15 \%$, no $2^{\circ}$ e $3^{\circ}$ ciclos, quando os totais nacionais são inferiores a 5\%. Outro estudo recente mostrou que, entre 2009 e 2014, a retenção escolar no ensino básico aumentou, tendo expressões muito distintas segundo a origem étnico-racial (Abrantes \& Roldão, 2019). No caso dos alunos afrodescendentes, o insucesso atingia, nesse período, mais do dobro do total nacional em todos os ciclos do ensino básico. Embora não existam estatísticas sobre os níveis de retenção dos alunos com "necessidades educativas especiais", os dados oficiais relativos a 2017/18 revelam que o número de alunos sinalizados cai de cerca de $10 \mathrm{mil}$, no $7^{\circ} \stackrel{0}{ }$ ano, para menos de $4 \mathrm{mil}$, no $12^{\circ}$ ano (DGEEC, 2019). É possível que muitos destes alunos abandonem sem concluir os estudos secundários.

No caso das provas nacionais, seja exames ou provas de aferição, o número de crianças que não alcança os resultados positivos tem sido sempre massivo, sobretudo no caso da Matemática. Recentemente, a administração educativa criou um indicador compósito, considerando que um "percurso de sucesso" implica concluir o ciclo de estudos no tempo esperado (sem retenções) e simultaneamente obter resultados positivos nas provas externas de final do ciclo (DGEEC \& JNE, 2018). Segundo este indicador, menos de $50 \%$ dos alunos do $3^{\text {o }}$ ciclo são considerados bem-sucedidos, sendo os resultados dos alunos muito condicionados pelo nível educativo e socioeconómico das respetivas famílias. As provas internacionais sobre as competências dos alunos não apresentam um quadro tão negativo. Segundo o relatório PISA, Portugal teve uma evolução positiva entre 2000 e 2018. Ainda assim, cerca de $10 \%$ de adolescentes com 15 anos não possuem as competências básicas nas três áreas: matemática, leitura e ciências (OCDE, 2019a).

Em suma, apesar de a generalidade das crianças e jovens dos 6 aos 18 anos de escolaridade frequentar hoje a escola, o que constitui uma evolução muito significativa face ao nosso passado recente, os níveis de aprendizagem 
e de qualificação alcançados permanecem assimétricos e com uma forte relação com as condições de vida dos alunos, o que constitui um sério desafio à concretização integral dos princípios da educação inclusiva.

\section{(c) GARANTIR A INTEGRAÇÃO EM ESCOLAS, CURRÍCULOS E TURMAS HETEROGÉNEOS E "REGULARES"}

Possivelmente a questão mais discutida do movimento da educação inclusiva impulsionado pela ONU, a partir da Declaração de Salamanca, tem sido a integração de todos os alunos com deficiência nas mesmas escolas que os restantes, no sentido de combater processos de segregação precoce e proporcionar o reconhecimento e a aprendizagem das diferenças (Haug, 2017). Estudos sobre as perceções e atitudes dos alunos perante a diferença corroboram o efeito positivo que tem a convivência com alunos com alguma incapacidade (Dias et al., 2016).

A este propósito, o número de crianças em instituições de educação especial reduziu-se, entre 2012-13 e 2017-18, de 1.344 para 982 (DGEEC, 2019), representando cerca de $0,1 \%$ do total de alunos, mas não existe informação sobre os motivos e consequências dessa separação. Um número mais significativo - em 2017/18, 13.430 alunos (1,1\% do total) - tem um currículo específico individual ou frequenta unidades de ensino especializado, sendo o seu tempo efetivo em turmas "regulares", na maior parte dos casos, inferior a $50 \%$. Aliás, o número de crianças com currículos específicos individuais cresceu de 2.099 em 2010/11 para 12.550 em 2017/18.

Outra questão é em que medida a generalidade dos alunos frequenta, efetivamente, ambientes escolares "regulares". As assimetrias socioeconómicas entre os alunos das diferentes escolas constituem um entrave efetivo, tanto à qualidade das aprendizagens como à igualdade de oportunidades. Neste caso, Portugal apresenta resultados preocupantes, com valores próximos dos observados nos Estados Unidos e que são transversais tanto à rede pública como à rede privada (Liebowitz et al., 2018). Na perspetiva de uma educação inclusiva em que aprender com a diferença constitui um objetivo central, será difícil argumentar que tais assimetrias não são limitadoras, além do efeito segregador e estigmatizador potenciado pelo facto de a comunicação social expor anualmente as desigualdades de resultados entre escolas na forma de rankings.

Segundo um estudo recente da DGEEC (2018) sobre o $2^{\circ}$ ciclo do ensino básico, enquanto existem municípios em que os alunos de diferentes contextos socioeconómicos se distribuem de forma equitativa pelas escolas públicas, por exemplo, no caso de Lisboa, o mais populoso, registam-se contrastes tão vincados como uma escola com $78 \%$ dos alunos com apoio social escolar (indicador de pobreza das famílias) e outra com $8 \%$. Se entrarmos em conta com a rede privada, os contrastes serão ainda mais vincados. Será importante fazer essa análise em todos os municípios e tanto no $1^{\circ}$ ciclo, onde o número de escolas tende a favorecer a homogeneidade dos públicos, como no 3 ํ ciclo, onde a oferta simultânea em escolas básicas e em escolas secundárias gera fenómenos de diferenciação. É certo que essas assimetrias são influenciadas por desigualdades existentes no território. Contudo, vale a pena discutir se a educação inclusiva não tem como requisito uma intervenção que mitigue fatores de exclusão que lhe são externos. Acresce que a investigação qualitativa (Abrantes \& Sebastião, 2010) tem mostrado que o contraste socioeconómico entre escolas tende a ser maior do que o territorial, devido a mecanismos de competição, diferenciação, exclusão e fechamento entre escolas. 
No caso da constituição das turmas, apesar de a legislação prever a utilização de critérios de heterogeneidade, cabe refinar a informação a nível nacional, uma vez que estudos de caso têm revelado desigualdades muito significativas (Sá \& Antunes, 2007; Abrantes \& Sebastião, 2010). Têm-se observado práticas de formação de turmas, com o objetivo de agrupar os alunos com base nas suas capacidades, percursos ou afinidades, o que reforça processos de diferenciação, segregação e exclusão.

Outra questão prende-se com as turmas "especiais" criadas no ensino básico para alunos em situação de insucesso repetido e risco de abandono (Rodrigues \& Nogueira, 2010), ao abrigo de modalidades como os percursos curriculares alternativos, os cursos de educação e formação, os programas integrados de educação e formação ou os cursos vocacionais (estes últimos, entretanto extintos). Existe ainda o caso singular do ensino artístico especializado, uma modalidade que permite a constituição de turmas com um currículo reforçado no domínio artístico, por opção dos pais e seleção de candidatos. Ao contrário do ensino secundário, composto por uma multiplicidade de cursos, o ensino básico tem uma estrutura curricular única, com o objetivo de garantir a todas as crianças uma base comum de competências e valores, evitando diferenciações e segregações precoces. Todavia, ao longo das últimas décadas germinaram estas várias modalidades que limitam a heterogeneidade das turmas, sem existir monitorização nacional sobre os efeitos na promoção da inclusão, das aprendizagens e dos percursos de vida dos jovens que as frequentam. Tal como nota Pacheco (2016), importa apurar se estas vias de diferenciação curricular, limitando a heterogeneidade das turmas, não constituem formas de segregação e exclusão dos alunos em condição mais vulnerável.

O que sabemos é que este universo - apesar de registar uma diminuição nos últimos cinco anos letivos - abrangeu, em 2019/20, 339 alunos do $1^{\circ}$ ciclo, 1.207 no $2^{\circ}$ ciclo e 15.110 no $3^{\circ}$ ciclo, neste último caso cerca de $5 \%$ do total de crianças a frequentar o respetivo ciclo. Mais uma vez, as condições de origem têm um peso significativo: por exemplo, mais de $12 \%$ dos alunos ciganos (DGEEC, 2020) frequentavam o $3^{\circ}$ ciclo do ensino básico, neste tipo de modalidades. Em 2014, cerca de $20 \%$ dos alunos afrodescendentes estavam na mesma situação (Abrantes e Roldão, 2019). Não sabemos qual a distribuição dos alunos acompanhados pelas equipas multidisciplinares de apoio à educação inclusiva.

\section{(d) GARANTIR O DIREITO AO RECONHECIMENTO E À PARTICIPAÇÃO}

As escolas reconhecerem as diferentes habilidades, culturas e interesses dos seus alunos e famílias, assegurando a todos condições de participação constitui outra das condições fundamentais para uma educação inclusiva.

Tal como nota Pacheco (2016), assistimos nas últimas décadas a um poderoso movimento internacional que estandardização do currículo e da avaliação, procurando afirmar um currículo tradicional e prescritivo, centrado na aprendizagem canónica da língua materna e da matemática, bem como na sua avaliação através de testes e exames, o que teve um particular impacto nas políticas educativas entre 2011 e 2015 . Estas orientações constituem um notável estreitamento do trabalho educativo e tendem a negligenciar o papel da escola no reconhecimento das diferentes habilidades, culturas e interesses dos alunos ou das suas famílias, contribuindo para a exclusão daquelas que não se adequam ou não se adaptam. 
As políticas curriculares, em Portugal, a partir de 2016, parecem ter divergido deste padrão, com a abolição dos exames nacionais no 4o e 6oanos de escolaridade, a publicação do Perfil dos Alunos à Saída da Escolaridade Obrigatória, o lançamento da Estratégia Nacional de Educação para a Cidadania, a afirmação da educação inclusiva (Decreto-Lei n.. 54/2018), o reforço da autonomia e flexibilidade curricular (Decreto-Lei n. ${ }^{\circ} 55 / 2018$ ) ou o novo ciclo da Avaliação Externa das Escolas. Ainda assim, trata-se de uma mudança de largo espectro, influenciada por vários fatores e será importante reforçar a bateria de indicadores que permitem observar as consequências no terreno. No relatório de acompanhamento ao projeto-piloto do novo quadro curricular, a OCDE (2018) não deixa de apontar esse desafio, recomendando a revisão do modelo de avaliação dos alunos, sobretudo no ensino secundário, ainda centrado na realização de testes escritos individuais à memorização de conteúdos disciplinares. Áreas de competência reconhecidas no referido Perfil, tais como o pensamento crítico e criativo, o relacionamento interpessoal, o bem-estar e saúde, entre outras, podem ser entendidas como demasiado subjetivas, uma vez que ainda não existem metodologias estabelecidas para a sua promoção e avaliação, nas escolas, o que constitui um desafio à sua afirmação.

No caso dos alunos com necessidades educativas especiais, houve um reporte anual de dados, mas que não incidia sobre as aprendizagens realizadas (DGEEC, 2019). As medidas aplicadas a estes alunos foram, geralmente, o apoio pedagógico individualizado, bem como a adequação curricular e dos processos de avaliação. Seria útil compreender se representam simplificações, estratégias alternativas ou a exploração de diferentes competências, de acordo com as habilidades e interesses dos alunos. Na nova configuração da educação inclusiva, o modelo de monitorização e avaliação não é ainda certo.

As próprias questões da segurança em ambientes escolares carecem de indicadores e de levantamentos periódicos de dados. Não existe uma sistematização das "ocorrências" e respetivos processos, seja nas escolas, seja na Inspeção-Geral da Educação e Ciência. Seria relevante, por exemplo, saber se os alunos com necessidades educativas especiais, com orientações sexuais minoritárias ou com origens étnicas diferenciadas se encontram mais expostos a atos de violência.

No caso da participação, os encarregados de educação e os alunos (do ensino secundário) podem eleger representantes para o Conselho Geral, mas faltam evidências de que estes representem efetivamente a diversidade das suas comunidades e tenham influência nas decisões tomadas. Formas mais orgânicas de participação ficam ao critério de cada escola e de cada professor, exceto no recente caso do Orçamento Participativo das Escolas. A Rede de Escolas para a Educação Intercultural abrange uma parte das escolas, mas não se conhecem as mais-valias em termos de inclusão. 0 desenvolvimento de estratégias neste campo parece depender, sobretudo, da iniciativa de cada escola, o que é redutor se as entendermos enquanto um direito de todas as crianças e uma condição para que o sistema seja inclusivo.

(e) GARANTIR UM ACOMPANHAMENTO INDIVIDUALIZADO, INTEGRADO E ESPECIALIZADO

Ao evitar segregações e estigmas, um sistema de educação inclusiva não pode providenciar uma educação "indiferenciada", que negligencie as diferenças e que opere sobre "o mínimo denominador comum", o que implica dotar as escolas de um conjunto de recursos e disposições que permitam acompanhar todos os alunos, na sua singularidade, e encontrar as soluções mais adequadas 
para garantir o bem-estar, o desenvolvimento e a aprendizagem de cada um. Se é certo que esse acompanhamento não deve ser realizado apenas ao nível da intervenção individual com certos alunos, uma mudança mais global que envolva toda a comunidade educativa não deixa de necessitar da intervenção de especialistas neste campo.

A este propósito, podemos destacar que as escolas públicas portuguesas conheceram um aumento significativo de profissionais especializados no acompanhamento e orientação dos alunos, depois de alguma quebra no período de austeridade (DGEEC, 2019). Em 2013/14, as escolas públicas registavam 5.300 docentes de educação especial, tendo esse valor ascendido a 7.518 em $2017 / 18$, o que representa um acréscimo de $42 \%$. As escolas contam ainda com técnicos especializados afetos à educação especial - num número que decaiu de 1.626 para 1.016, entre 2012/13 e 2017/18 - e com técnicos disponibilizados pelos Centros de Recursos para a Inclusão - que se têm mantido na ordem dos 500. A área terapêutica com maior intervenção é a da psicologia (529 técnicos), mas também a terapia da fala (183 técnicos) e a língua gestual portuguesa (173 técnicos) alcançam uma dimensão expressiva.

Ainda assim, existe uma noção bastante alargada de que os recursos são insuficientes para garantir resposta às necessidades (Liebowitz et al., 2018). Por um lado, apesar de uma redução do número total de crianças, os alunos sinalizados para um acompanhamento especializado têm vindo a aumentar, praticamente duplicando no espaço de uma década, de $46.950 \mathrm{em}$ 2010/11 para 88.023 em 2017/18, o que aumentou a pressão sobre os profissionais das escolas. Esta tendência resulta certamente de uma maior capacidade de diagnóstico precoce, bem como da redução do abandono escolar. Contudo, poderá igualmente relevar dificuldades dos professores em lidar com a diferença, recorrendo mais a apoio especializado do que noutros países (Liebowitz et al., 2018). De acordo com o relatório TALIS 2018 (OCDE, 2019b), o trabalho com os alunos com necessidades educativas especiais é uma das áreas de desenvolvimento profissional que mais docentes portugueses (27\%) reportam necessidades de formação.

Um estudo recente sobre as perceções dos educadores de infância e dos professores do $1^{\text {o }}$ ciclo mostrou uma adesão maioritária ao conceito de educação inclusiva, mas dependente de vários fatores (Rodrigues \& Ferreira, 2017). Se a larga maioria concorda em lecionar uma turma que inclua alunos com atraso global de desenvolvimento ou perturbação de hiperatividade e défice de atenção, já no caso de alunos com incapacidade intelectual ou autismo a maioria dos profissionais apenas o aceitaria com apoio especializado, sendo que o mesmo ocorre para alunos com paralisia cerebral, mas neste caso mais de um quarto dos inquiridos considera que nem mesmo com apoio especializado estes alunos deveriam frequentar a sala de aula. 0 estudo mostrou que essa aceitação está fortemente relacionada com a formação que os profissionais têm para lidar com os diferentes perfis de alunos.

Por outro lado, o conceito de educação inclusiva está associado a uma crítica a esta visão restrita das "necessidades educativas especiais". A este propósito, existem recursos dispersos por vários programas socioeducativos e de combate ao insucesso escolar, mas raramente considerados dentro das políticas de educação inclusiva, ao contrário do que ocorre em vários países europeus (AENEEI, 2018) e não existem dados sistematizados que permitam entender o volume dos recursos envolvidos, a sua evolução e os impactos da sua ação. Um estudo recente da OCDE (Liebowitz et al., 2018) sobre os recursos no sistema educativo português fez um mapeamento mais alargado do que 
designou "financiamento para a equidade". Este estudo concluiu que o investimento público na educação das crianças com necessidades educativas especiais passou de 197 milhões de euros, em 2010/11 (3,3\% da despesa em educação), para 300 milhões, em 2016/17 (5,9\% do total). Os programas de cariz socioeducativo conheceram também um reforço significativo do investimento, durante este período, embora em patamares bastante mais modestos, exceto no caso do apoio social escolar que tem ultrapassado os 100 milhões de euros anuais. Esta tendência de crescimento é tanto mais significativa quando o total da despesa com a educação, assim como o número total de alunos, não aumentaram ao longo da última década. Ainda assim, o relatório frisa que os recursos destinados à promoção do sucesso escolar, nomeadamente dos alunos em situações sociais mais vulneráveis, representam ainda uma parcela reduzida do investimento público em educação. Não estando estabilizados, nem um sistema político-administrativo nem um quadro profissional para esta área de intervenção, estes recursos são dependentes de projetos de curto prazo e, por isso, implementados em condições temporárias e precárias, o que dificulta a consistência do trabalho, bem como o seu reconhecimento por parte das comunidades. Acresce a escassa formação dos docentes para trabalhar em contextos socioeducativos multiculturais (OCDE, 2019b). Mesmo as iniciativas nacionais já com alguma longevidade e dimensão, como é o caso do programa de Ensino do Português Língua Não Materna (Madeira et al., 2014), muitos dos profissionais que têm assegurado esta oferta são docentes do ensino "regular", frequentemente, sem formação específica para lecionar esta área.

\section{NOTAS FINAIS}

O presente artigo propõe um quadro conceptual e analítico para estudar o desígnio da educação inclusiva, nas suas várias dimensões, aplicando-o ao caso português. Procurou-se incluir as questões dos alunos com deficiência no espetro mais alargado da diversidade na escola, em particular, dos alunos em situação de insucesso, abandono e exclusão, acompanhando a legislação nacional e a documentação internacional sobre educação inclusiva. Identificaramse assim condições fundamentais para analisar o carácter inclusivo de um sistema educativo, tendo-se discutido como estas são passíveis de se concretizar num conjunto de indicadores.

Certamente, uma análise tão ampla não permite uma recolha exaustiva de perspetivas teóricas e de estudos empíricos. No caso dos estudos, privilegiámos as fontes oficiais, não apenas porque geralmente são aquelas que permitem uma visão panorâmica e longitudinal da realidade nacional, mas também porque o compromisso político com a educação inclusiva implica estabelecer, recolher, analisar e divulgar, em articulação com a comunidade científica, um conjunto de indicadores que permitam aferir avanços nesta área. Assim sendo, o que esta análise permitiu observar foi que, no plano da educação inclusiva, a par de avanços muito significativos que ocorreram em Portugal nas últimas duas décadas, subsistem desafios importantes e a centralidade que assumiu este conceito não deixa de colocar um novo patamar de exigência, tanto à recolha e análise de dados, como às políticas e práticas educativas.

\section{REFERÊNCIAS}


Abrantes, P. (2013). A Escola da Vida: Socialização e Biografia(s) da Classe Trabalhadora. Mundos Sociais.

Abrantes, P., \& Roldão, C. (2019). The (mis) education of African descendants in Portugal: Towards vocational traps? Portuguese Journal of Social Science, 18(1), 27-55. https://doi.org/10.1386/pjss.18.1.27_1

Abrantes, P., Roldão, C., Amaral, P., \& Mauritti, R. (2013). Born to fail? Some lessons from a national programme to improve education in poor districts. International Studies in Sociology of Education, 23(1), 17-38. https://doi.org/10.1080/09620214.2013.770206

Abrantes, P., \& Sebastião, J. (2010). Portões que se abrem e que se fecham: Processos de inclusão e de segregação na escola pública portuguesa. In A. Dornelas et al. (Orgs.), Portugal Invisível. Mundos Sociais.

AENEEI - Agência Europeia para as Necessidades Especiais e a Educação Inclusiva (2018). Financing Policies for Inclusive Education Systems: Resourcing Levers to Reduce Disparity in Education. AENEEI.

Ainscow, M., \& César, M. (2006). Inclusive education ten years after Salamanca: Setting the agenda. European Journal of Psychology of Education, 21(3), 231-238. https://doi.org/10.1007/BF03173412

Alonso, J. D., Castedo, A. L., Juste, M. R. P., \& Varela, E. V. (2015). Integración o inclusión: El dilema educativo en la atención a la diversidad. Revista Portuguesa de Educação, 28(2), 31-50. https://doi.org/10.21814/rpe.7749

Álvares, M., Abrantes, P., \& Dantas, P. C. (2017). La lucha contra el abandono educativo temprano: políticas y prácticas en red. In Prevención, Intervención y Compensación del Abandono Educativo Temprano (pp. 211-241). Ministerio de Educación, Cultura y Deporte.

Barton, L. (1997). Inclusive education: romantic, subversive or realistic? International Journal of Inclusive Education, 1(3), 231-242. https://doi.org/10.1080/1360311970010301

Borges, M. L., Martins, M. H., Lucio-Villegas, E., \& Gonçalves, T. (2017). Desafios institucionais à inclusão de estudantes com Necessidades Educativas Especiais no Ensino Superior. Revista Portuguesa de Educação, 30(2), 7-31. https://doi.org/10.21814/rpe.10766

Casa-Nova, M. J. (2005). (I)migrantes, diversidades e desigualdades no sistema educativo português: balanço e perspectivas. Ensaio: Avaliação e Políticas Públicas em Educação, 13(47), 181-215. https://doi.org/10.1590/S010440362005000200005

Casanova, M. A. (2018). Educação inclusiva: Por quê e para quê? Revista Portuguesa de Educação, 31 (núm. esp.), 42-54. https://doi.org/10.21814/rpe.15078

CNE - Conselho Nacional de Educação (2018). Estado da Educação 2017. CNE.

DGEEC (2018). Assimetrias de contexto socioeconómico entre escolas públicas - $2^{\circ}$ ciclo. http://www.dgeec.mec.pt/np4/407/

DGEEC (2019). Necessidades Especiais de Educação 2017/2018.

http://www.dgeec.mec.pt/np4/224/

DGEEC - Direção Geral de Estatísticas da Educação e Ciência (2020).

Perfil Escolar da Comunidade Cigana. http://www. https://www.dgeec.mec.pt/np4/97/ DGEEC (2021). Educação em Números 2021.

https://www.dgeec.mec.pt/np4/96/

DGEEC \& JNE - Júri Nacional de Exames (2018). Provas Finais e Exames Nacionais: Principais Indicadores. https://www.dgeec.mec.pt/np4/441/ 
Dias, P., Sousa, J., Gonçalves, M., Flores, P., \& Pérez, J. D. (2016). Atitudes dos pares sobre a inclusão: Contributos da adaptação de um instrumento. Psicologia, 30(2), 95-106. https://doi.org/10.17575/rpsicol.v30i2.1099

Eurydice (2019). Key Data on Early Childhood Education and Care in Europe. Publicações da União Europeia. https://doi.org/10.2797/894279

Fernandes, D. (coord.), Neves, C., Tinoca, L., Viseu, S., \& Henriques, S. (2018). Políticas Educativas e Desempenho de Portugal no PISA (2000-2015). Instituto de Educação da Universidade de Lisboa.

Freire, S. (2008). Um olhar sobre a inclusão. Revista de Educação, 16(1), $5-20$.

Hardy, I., \& Woodcock, S. (2015). Inclusive education policies: discourses of difference, diversity and deficit. International Journal of Inclusive Education, 19(2), 141-164. https://doi.org/10.1080/13603116.2014.908965

Haug, P. (2017). Understanding inclusive education: ideals and reality. Scandinavian Journal of Disability Research, 19(3), 206-217. https://doi.org/10.1080/15017419.2016.1224778

Johnstone, C., Lazarus, S., Lazetic, P., \& Nikolic, G. (2019). Resourcing inclusion: Introducing finance perspectives to inclusive education policy rhetoric. Prospects, 47(4), 339-359. https://doi.org/10.1007/s11125-018-9432-2

Liebowitz, D., González, P., Hooge, E., \& Lima, G. (2018). OECD Reviews of School Resources: Portugal. OCDE.

Madeira, A., Teixeira, J., Botelho, F., Costa, J., Deus, S., Fiéis, A., Sousa Martins, A., Machete, T., Militão, P., \& Pessoa, I. (2014). Avaliação de Impacto e Medidas Prospetivas para a Oferta do Português Língua Não Materna (PLNM) no Sistema Educativo Português. DGE.

https://www.dge.mec.pt/sites/default/files/Curriculo/EBasico/PLNM/estudo_plnm.pd f

Messiou, K. (2017). Research in the field of inclusive education: time for a rethink? International Journal of Inclusive Education, 21(2), 146-159.

https://doi.org/10.1080/13603116.2016.1223184

Neiva, C., Ferreira, M. J., \& Seabra, F. (2017). Perspectivas sobre equidade e inclusão: atores e contextos. In M. L. Borges, C. Luísa \& M. H. Martins (Coords.), I/ Congresso Internacional Direitos Humanos e Educação Inclusiva: Múltiplos olhares (pp. 285-299). Universidade do Algarve.

OCDE - Organização para a Cooperação e Desenvolvimento Económico (2018). Curriculum Flexibility and Autonomy in Portugal: An OECD Review. OCDE. https://www.oecd.org/education/2030/Curriculum-Flexibility-and-Autonomy-inPortugal-an-OECD-Review.pdf

OCDE (2019a). PISA 2018 Results (Volume I): What Students Know and Can Do. OCDE.

OCDE (2019b). TALIS 2018 Results (Volume l): Teachers and School Leaders as Lifelong Learners. OCDE.

Pacheco, J. A. (2016). Currículo e inclusão escolar: (in)variantes educacionais e curriculares. Teias, 17(46), 110-124.

https://doi.org/10.12957/teias.2016.25648

Pereira, C. D., Lunardi-Mendes, G. M., \& de Brito Pacheco, J. A. (2018). Políticas de inclusão escolar no Brasil e em Portugal: desafios para a justiça curricular. Teias, 19(55), 36-53. https://doi.org/10.12957/teias.2018.37597

Porter, G. (2014). A recipe for successful inclusive education: three key ingredients revealed. Interacções, 10(33), 10-17. https://doi.org/10.25755/int.6729 
Rajput, M. V., Das, H., \& Goswami, P. P. (2018). The challenges towards meaningful inclusive education. International Journal of Educational Planning \& Administration, 8(1), 7-10. https://doi.org/10.1080/09687590903283464

Rodrigues, D. (2006). Dez ideias (mal) feitas sobre a educação Inclusiva. In D. Rodrigues (Org.), Inclusão e Educação: Doze Olhares Sobre a Educação Inclusiva. Summus Editorial.

Rodrigues, D., \& Nogueira, J. (2010). Educação especial e inclusiva em Portugal: factos e opções. Revista de Educación Inclusiva, 3(1), 97-109. https://doi.org/10.1590/S1413-65382011000100002

Rodrigues, M., \& Ferreira, M. (2017). A inclusão de crianças com necessidades educativas especiais no ensino regular em Portugal: a opinião de educadores de infância e de professores do $1^{\circ}$ ciclo do ensino público e privado. Revista Brasileira de Educação Especial, 23(1), 37-52. https://doi.org/10.1590/s141365382317000100004

Sá, V., \& Antunes, F. (2007). Públicos e (des)vantagens em educação: escolas e famílias em interacção. Revista Portuguesa de Educação, 20(1), 129-161.

Sampaio, C., \& Morgado, J. (2015). As atitudes dos professores do primeiro ciclo do ensino básico face à educação inclusiva de alunos com necessidades educativas especiais. Interacções, 10(33), 163-188. https://doi.org/10.25755/int.6734

Sanches, I., \& Teodoro, A. (2006). Da integração à inclusão escolar: cruzando perspectivas e conceitos. Revista Lusófona de Educação, 8, 63-83. https://revistas.ulusofona.pt/index.php/rleducacao/article/view/691

Seabra, F. (2017). Equidade e inclusão: sentidos e aproximações. In J.A. Pacheco, G. Mendes, F. Seabra, \& I. C. Viana (Orgs.), Currículo, Inclusão e Educação Escolar (pp. 763-781). CIEd/Instituto de Educação da Universidade do Minho.

Silva, M. O. E. da (2009). Da exclusão à inclusão: concepções e práticas. Revista Lusófona de Educação, 13, 135-153. https://revistas.ulusofona.pt/index.php/rleducacao/article/view/562

Strieder, R., \& Nogaro, N. (2016). No controverso desafio da educação inclusiva: um convite para pensar a complexidade humana. Revista Portuguesa de Educação, 29(1), 51-73. https://doi.org/doi:10.21814/rpe.8799

Thomas, G. (2013). A review of thinking and research about inclusive education policy, with suggestions for a new kind of inclusive thinking. British Educational Research Journal, 39(3), 473-490.

https://doi.org/10.1080/01411926.2011.652070

Vlachou, A. (2004). Education and inclusive policy-making: implications for research and practice. International Journal of Inclusive Education, 8(1), 3-21. https://doi.org/10.1080/1360311032000139449

Waitoller, F. R., \& Kozleski, E. B. (2015). No stone left unturned: Exploring the convergence of New Capitalism in inclusive education in the U.S. Education Policy Analysis Archives, 23(37). https://doi.org/10.14507/epaa.v23.1779

\section{LEGISLAÇÃO CONSULTADA}

Decreto-Lei n. ${ }^{\circ}$ 54/2018, Diário da República n. ${ }^{\circ}$ 129/2018, Série I de 2018-07-06.

Decreto-Lei n. ${ }^{\circ}$ 55/2018, Diário da República n. ${ }^{\circ}$ 129/2018, Série I de 2018-07-06.

Portaria n. ${ }^{\circ}$ 69/2019, Diário da República n. ${ }^{\circ}$ 40/2019, Série I de 2019-

02-26. 
Informação do autor:

i Universidade Aberta e ISCTE-Instituto Universitário de Lisboa, Portugal.

https://orcid.org/0000-0001-9572-9563

Toda a correspondência relativa a este artigo deve ser enviada para:

Pedro Abrantes

Universidade Aberta, Departamento de Ciências Sociais e de Gestão, Palácio Ceia, R. da Escola Politécnica n 141, 1250-100 Lisboa.

pedro.abrantes@iscte.pt

Recebido em 7 de outubro de 2019

Aceite para publicação em 20 de abril de 2021 


\section{Inclusive education: Analytical framework and application to the Portuguese case}

\section{ABSTRACT}

The concept of inclusive education has gained undeniable centrality in education policies. Based on the identification of a set of theoretical approaches and research on this subject, this article proposes an analytical framework to discuss the progress, weaknesses and challenges of education systems and programs committed to the purpose of inclusive education, applying this framework to discuss the evolution of the Portuguese education system in the first two decades of the 21st century. In a nutshell, this analysis evidences an important progress, but also persistent gaps, including on the production of systematic information and knowledge.

Keywords: Inclusion; Policies; Learning; Indicators 


\section{Educación inclusiva: propuesta de un marco analítico y aplicación al caso portugués}

\section{RESUMEN}

El concepto de educación inclusiva ha adquirido una innegable centralidad en el ámbito de las políticas educativas. Basado en la identificación de un conjunto de planteamientos teóricos e investigaciones sobre el tema, este artículo propone un marco de análisis para discutir el progreso, las debilidades y los retos de los sistemas y programas educativos comprometidos con el propósito de la educación inclusiva, aplicando este marco para discutir la evolución del sistema educativo portugués en las dos primeras décadas del siglo XXI. Este análisis ha permitido observar avances importantes, pero también brechas persistentes, incluyendo a nivel de la producción sistemática de información y conocimiento.

Palabras-clave: Inclusión; Políticas; Aprendizaje; Indicadores 